\title{
PROPOSALS REGARDING A WEAPONS REVIEW PROCESS IN SOUTH AFRICA (PART 2)
}

\author{
Ashley Moorhouse*
}

$L L B$

Advocate of the High Court of South Africa

Port Elizabeth

David Abrahams

BJuris LLB LLM LLM

Lecturer in Law

Nelson Mandela Metropolitan University

Port Elizabeth

SUMMARY

This article forms the final part of a two-part series dealing with submissions regarding the implementation of a weapons review process in compliance of South Africa's obligations under article 36 of Protocol I Additional to the 1949 Geneva Conventions.

Part I hereof was published in 2010 (Volume 31 1) Obiter 34-56 and dealt with the introductory and legal aspects of weapons review processes. Part 2, which follows hereunder, deals with the practical aspects of the weapons review process, namely the structure and composition of the review body and the various elements of the process of the review that need to be considered and regulated. The guidelines enunciated in this article attempt to ensure that South Africa complies with its international legal obligations under article 36. An overall conclusion of the series is dealt with at the end of this article.

\section{THE REVIEW BODY}

\section{Introduction}

The correct structure is vital to the efficient and satisfactory operation of a weapons review body. Furthermore, the data that must be considered by the body in order to make informed and correct legal determinations necessitate

Ashley Moorhouse was a registered final year Baccalaureus Legum (LLB) student at the Faculty of Law, Nelson Mandela Metropolitan University, Port Elizabeth at the time of writing this article. 
that the composition of the body must incorporate the relevant experts adequately. These two aspects, structure and composition, are now to be elaborated upon.

\section{Structure}

The responsibility for carrying out a legal review may be entrusted to one of three systems: a committee made up of permanent and ad hoc representatives of the relevant sectors and departments; ${ }^{1}$ a mixed system whereby a single official, such as the Chief of the South African National Defence Force, is advised by a standing committee that carries out the review $^{2}$ or a single official, such as the Chief of Defence Legal Services, who consults the relevant sectors, departments and experts. ${ }^{3}$

It is submitted that a standing committee of permanent and ad hoc experts, from the relevant fields, sectors and departments, is the favoured structure for the review process to take in South Africa. It is this structure that would ensure the independence and impartiality of the review most adequately and thus guarantee the legitimacy of the process and the proper fulfilment of its purpose. Moreover, the conducting of a weapons review by such a committee has the advantage of guaranteeing that the relevant experts are present to assess the weapon being reviewed. ${ }^{4}$ Furthermore, review processes focused around a single official can give rise to delays depending upon the number of weapons that such official is required to review. ${ }^{5}$

1 See Défense, Etat-Major de la Défense, Ordre Général - J/836 (18 July 2002) (hereinafter "Belgian Order"]; Beschikking van de Minister van Defensie nr.458.614/A, 5 May 1978 (hereinafter "Dutch Directive"); Direktiv om folkerettslig vurdering av vapen, krigforingsmetoder og krigforingsvirkemidler, Ministry of Defence, 18 June 2003 (hereinafter "Norwegian Directive"); and Förordning om folkrättslig granskning av vapenproject, SFS 1994:536 s 8 (hereinafter "Swedish Ordinance"). See also Sandoz, Swinarski and Zimmermann Commentary on the Additional Protocols of 8 June 1977 to the Geneva Conventions of 12 August 1949 (1987) 1463; Danish Red Cross Reviewing the Legality of New Weapons December 2000 (hereinafter "Danish RC Report") par 6.2-6.3; and ICRC Advisory Service on International Humanitarian Law "New Weapons" (2001) (hereinafter "ICRC Advisory Service") 1.

2 See Belgian Order s 2(b) and Norwegian Directive s 2.1. See also ICRC Advisory Service 1; and Daoust "ICRC Expert Meeting on Legal Reviews of Weapons and the SIrUS Project" June 200183 IRRC 539540.

3 See Legal Review of New Weapons, Australian Department of Defence Instruction (General) OPS 44-1, 2 June 2005 (hereinafter "Australian Instruction") s 6; and Review of Legality of Weapons under International Law, US Department of Defense Instruction 5500.15 (16 October 1974) (hereinafter "US Instruction") s IV.A. See also McClelland "The Review of Weapons in Accordance with Article 36 of Additional Protocol I" June 200385 IRRC 397 403; Danish RC Report par 6.4; Parks, Special Assistant to the Judge Advocate General of the Army, Washington DC, US, paper presented to an informal technical meeting hosted by the Government of Switzerland (Darlingen, Switzerland, 12-14 June 2002) (hereinafter "Parks's Paper 2002"); ICRC Advisory Service 1; and Daoust June 200183 IRRC 540 .

4 McClelland June 200385 IRRC 403.

5 Ibid. 


\section{Composition}

\section{Introduction}

In order to assess the legality of a particular weapon adequately, the review should incorporate a rigorous, multi-disciplinary process encompassing a wide range of legal, technical, medical and environmental considerations.

The review body should review with particular scrutiny those weapons that injure by means other than explosives, projectile force or burns and that cause health effects with which medical personnel are unfamiliar. ${ }^{7}$ Also, the body must take cognisance of the fact that the weapon's effects will result from a combination of its design and the manner in which it is to be used, and thus the review body must examine both the weapon's design and characteristics and the method in which it will be used. ${ }^{8}$ The above two submissions are clear examples of the multi-disciplinary nature of the review.

It is submitted that the process should involve experts from various relevant disciplines and the composition of the body is fundamentally dependent upon the empirical data required for a competent review. ${ }^{9}$

\section{Relevant empirical data}

\section{Technical data}

The starting point of a legal assessment of a particular weapon would logically be a consideration of its design and technical characteristics. Data relevant to such a consideration would include a full, detailed technical description of the weapon, which would cover the design, material composition and fusing system of the weapon ${ }^{10}$ and the "range, speed, shape, materials, fragments, accuracy, desired effect, and nature of system

6 28th International Conference of the Red Cross and Red Crescent (Geneva, Switzerland, 26 December 2003) Agenda for Humanitarian Action (hereinafter "Agenda for Humanitarian Action") Action 2.5.1-2.5.2; Lawand, Coupland and Herby A Guide to the Legal Review of New Weapons, Means and Methods of Warfare - Measures to Implement Article 36 of Additional Protocol I of 1977 (2006) 17; ICRC Advisory Service 1; Daoust, Coupland and Ishoey "New Wars, New Weapons? The Obligation of States to Assess the Legality of Means and Methods of Warfare" June 200284 IRRC 345352 and 361-362; Daoust 2001 83 IRRC 541-542; Lawand "Reviewing the Legality of New Weapons, Means and Methods of Warfare" December 200688 IRRC 925 929; and Summary Report by the ICRC, Expert Meeting on Legal Reviews of Weapons and the SIrUS Project (Jongny sur Vevey, Switzerland, 29-31 January 2001) (hereinafter "ICRC Summary Report of the Expert Meeting"). See further McClelland June 200385 IRRC 400.

7 Agenda for Humanitarian Action Action 2.5.2; Daoust et al June 200284 IRRC 353-354; ICRC Summary Report of the Expert Meeting; Daoust 200183 IRRC 541-542. See also the proposals contained in ICRC "The SIrUS Project and reviewing the legality of new weapons" (January 2000) and Lawand December 200688 IRRC 929. Lawand et al 17.

9 See Agenda for Humanitarian Action Action 2.5.1.

10 Lawand et al 18. 
or subsystem employed for firing, launching, releasing or dispensing"11; the intended use ${ }^{12}$ and types of targets for which the weapon is designed and the weapon's damage and injury mechanisms. Together with the abovedescribed technical description of the weapon, its technical performance must also be considered.

The technical performance of the weapon is particularly relevant in determining whether its use could have indiscriminate effects. ${ }^{13}$ Relevant data in this regard would be the accuracy of the weapon's targeting mechanism, including the reliability of the mechanism, failure rates and the sensitivity of unexploded ordnance; the area effect of the weapon and the capability of limiting the weapon's foreseeable effects, including the degree to which a weapon will present a risk to the civilian population after its military purpose is served. ${ }^{14}$ The design-dependent effects of the weapon should also be taken into account. ${ }^{15}$

\section{Medical data}

Medical data is of importance as it is this data that is to be weighed against the intended military purpose or expected military advantage of the weapon so as to determine the probability of the weapon causing superfluous injury or unnecessary suffering. ${ }^{16}$

The review process must take cognisance of the injuries and effects that the weapon under review would be capable of inflicting upon persons. ${ }^{17}$ The review body would require data regarding the injury mechanism of the weapon; ${ }_{19}^{18}$ the size of the wound expected when it is used for its intended purpose $;{ }^{19}$ whether it would cause anatomical injury, anatomical disability or

11 See US Department of Air Force Instruction 51-402, Weapons Review, 13 May 1994 (implementing US Department of Air Force Policy Directive 51-4, Compliance with the Law of Armed Conflict, 26 April 1993 and US Department of Defence Directive 5100.77, DoD Law of War Program, 9 December 1998) (hereinafter "US Air Force Instruction") s 1.2.1.

12 McClelland June 200385 IRRC 408

13 See Lawand et al 18. See also McClelland June 200385 IRRC 408-409.

14 Lawand et al 18; McClelland June 200385 IRRC 408-409; and Lawand December 200688 IRRC 929.

15 See Daoust et al June 200284 IRRC 353; Coupland and Herby "Review of the Legality of Weapons: A New Approach The SIrUS Project" September 1999835 IRRC 583-592 and McClelland June 200385 IRRC 399-400. See further Coupland The SIrUS Project: Towards a Determination of Which Weapons Cause "Superfluous Injury or Unnecessary Suffering" (1997).

16 Daoust et al June 200284 IRRC 350 and 353; Henckaerts and Doswald-Beck Customary International Humanitarian Law (2005) Vol I Rule 45 151, Rule 70240 and 240 fn 23; and McClelland June 200385 IRRC 400 and 406-407. See also ICRC Symposium The Medical Profession and the Effects of Weapons (Montreux, Switzerland, 1996), ICRC, Geneva, 1996; Coupland and Herby September 1999835 IRRC 583-592; and Beckett "Interim Legality: A Mistaken Assumption? - An Analysis of Depleted Uranium Munitions under Contemporary International Law" 20043 Chinese Journal of International Law 43 61-66. See further Legality of the Threat or Use of Nuclear Weapons, Advisory Opinion of 8 July 1996, ICJ Reports 1996 (hereinafter "Nuclear Weapons AO"] 78; Daoust June 200183 IRRC 541; and Lawand December 200688 IRRC 929.

17 Coupland and Herby September 1999835 IRRC 583-592; and McClelland June 200385 IRRC 407. See also US Air Force Instruction s 1.2.1. See further ICRC Advisory Service 2.

18 Daoust et al June 200284 IRRC 353.

19 McClelland June 200385 IRRC 400. 
disfigurement that is specific to its design; ${ }^{20}$ the number of victims that would be injured by $\mathrm{it}^{21}$ and the expected field mortality rate when it is used for its intended purpose. ${ }^{22}$

Additional data would be required where the weapon causes injury by a mechanism other than explosive or projectile force or otherwise causes health effects that are qualitatively or quantitatively different from those of existing weapons. ${ }^{23}$ Such data would include whether all relevant scientific evidence pertaining to the foreseeable effects on humans has been gathered; the impact of the injury mechanism upon the health of victims; whether the injuries caused would be recognized by health professionals, be manageable under field conditions and be treatable in a reasonably equipped medical facility; data regarding any predictable or expected long term or permanent alteration to the victims' psychology or physiology and whether the mortality rate in hospitals is expected to be high. ${ }^{24}$

\section{Environmental data}

When reviewing a weapon, the effects of that weapon upon the environment must be considered. Particular attention should be given to considerations of the probability of the weapon causing excessive incidental damage or widespread, long-term severe damage to the environment. ${ }^{25}$

Data ascertaining whether the weapon is specifically designed to cause environmental modification ${ }^{26}$ or to damage the natural environment ${ }^{27}$ would be relevant, as would be data determining the possible extent and form of damage to the natural environment caused by the weapon, whether directly or indirectly. ${ }^{28}$ Furthermore, data regarding the impact of any environmental damage on the civilian population, taking into account both the weapon's direct and indirect impact, would need to be compiled. ${ }^{29}$ Information concerning the duration of the environmental damage caused and the possibility, practicality and time necessary to reverse the damage would also be relevant. ${ }^{30}$ It is vital for the body to have data at its disposal indicating

20 Ibid; Daoust et al June 200284 IRRC 353; and Coupland and Herby September 1999835 IRRC 583-592.

21 McClelland June 200385 IRRC 407.

22 McClelland June 200385 IRRC 400; and Daoust et al June 200284 IRRC 353.

23 See Expert Meeting on Legal Reviews of Weapons and the SIrUS Project (Jongny sur Vevey, Switzerland, 29-31 January 2001); and Agenda for Humanitarian Action 2.5.2. See also ICRC Advisory Service 2.

24 See also McClelland June 200385 IRRC 400.

25 See Protocol Additional to the Geneva Conventions of 12 August 1949; and relating to the Protection of Victims of International Armed Conflicts (Protocol I) 1977 (hereinafter "Additional Protocol I") Article 35(3) and 55. See also Henckaerts and Doswald-Beck Customary IHL Vol I Rule 44-45 147 and 151. See also Convention on the Prohibition of Military or any Other Hostile Use of Environmental Modification Techniques 1978 (hereinafter "ENMOD") Article 1.1.

26 See ENMOD Article 1.1.

27 Henckaerts and Doswald-Beck Customary IHL Vol I Rule 45151.

28 Lawand et al 20.

29 Ibid.

30 Ibid. 
whether adequate scientific studies of the effects on the natural environment have been conducted and thoroughly examined. ${ }^{31}$

\section{Other relevant data}

The review body may need to take into consideration data from various other fields of study when reviewing the legality of a weapon. Thus, although the above three fields of data would be needed in the majority of reviews, other relevant data must not be overlooked where such additional forms of data are required to make an informed decision on the legality of a particular weapon. Such data include information regarding the military necessity and intended use of the new weapon, the implications of that weapon's proliferation and whether another weapon, mean or method of warfare could achieve the same military purpose. ${ }^{32}$

\section{Conclusion}

As the material scope of the review would require the review body to consider a wide range of expert fields, the review should involve a multidisciplinary approach that ensures the participation of the necessary experts in the relevant fields, including legal, health, environmental, military and arms technology experts. ${ }^{33}$ This is essential, as it would allow the review process to assess the information relating to a weapon fully and to make an informed determination on its legality.

These experts could be drawn either from the private sector or from governmental departments. ${ }^{34}$ Of necessity, the review would need to include an expert in the field of international humanitarian law, who could be drawn from the ranks of the Defence Legal Services Division, the legal advisors appointed to the armed forces. ${ }^{35}$ Further government departments from which experts could be drawn include the Departments of Defence, Environmental Affairs and Tourism, and Health and Foreign Affairs. Relevant Department of Defence structures from which experts could be drawn would include the South African National Defence Force, the Defence

\footnotetext{
Ibid.

32 See Daoust et al June 200284 IRRC 352; ICRC Advisory Service 2; and Coupland and Herby September 1999835 IRRC 583-592.

33 See McClelland June 200385 IRRC 403; Lawand et al 22; and Daoust et al June 200284 IRRC 355 and 357. See also Agenda for Humanitarian Action Action 2.5.2. See further Australian Instruction s 6; and US Instruction s IV.A.

34 See Australian Instruction s 6; and US Instruction s IV.A.

35 Especially the Directorate for Operational Law. See [South African] Department of Defence Strategic Business Plan FY2005/2006 to 2007/2008 (hereinafter "DoD SBP 2005-2008") 19 Figure 3.2; [South African] Department of Defence Strategic Business Plan 2007 (MTEF FY 2007/08-2009/10) (hereinafter "DoD SBP 2007") 19 Figure 3.2 and http://www.dlsdiv.mil.za. See also Lawand et al 22.

36 Including experts in international law. Lawand et al 22; and Daoust et al June 200284 IRRC $355 \mathrm{fn} 29$. See also Belgian Order s 4(c); Norwegian Directive s 4.3; Danish RC Report 28; http://www.sweden.gov.se/sb/d/2060/a/28161 (accessed 2008-08-15); ICRC Advisory Service 1; and Daoust June 200183 IRRC 540.
} 
Secretariat, the South African Military Health Services, ${ }^{37}$ the Logistics Division, ${ }^{38}$ the Finance Board, Department of Defence Acquisition and Procurement Division, ${ }^{39}$ the Matériel Board ${ }^{40}$ and the authorities responsible military engineering and operative planning. ${ }^{41}$

Experts could also be drawn from various non-governmental bodies in various sectors, including military research institutes, private legal practitioners, tertiary education institutes and strategic industry components. $^{42}$ It is submitted that certain experts should have a permanent place on the review body, such as experts from fields that will need to be considered in almost all weapons reviews, for example weapons design and medical experts, whilst certain experts could be attached to the body on an ad hoc basis when their field of expertise is required by the review of a certain type of weapon, such fields including ophthalmology, laser technology and psychiatry.

\section{THE REVIEW PROCESS}

\section{Introduction}

Regarding the process of the review, a number of elements need to be considered and regulated. These elements are the initiation of the review, the integration of the process into the weapons acquisition process, methods of data collection, various aspects regarding the conclusions of the review body, the record-keeping of such conclusions and continued in-service legal monitoring of reviewed weapons.

37 See Belgian Order s 4(a)(1); Australian Instruction s 6 and US Army Regulation s 5(d). See also DoD SBP 2005-2008 19 Figure 3.2 and DoD SBP 200719 Figure 3.2.

38 Including the Logistics Board. DoD SBP 2005-2008 19 Figure 3.2 and DoD SBP 200719 Figure 3.2.

39 See http://www.secdef.mil.za/structure/structure.htm (accessed 2008-09-19).

40 DoD SBP 200717 Figure 3.1.

41 Included here could be representatives from the following SANDF structures: the Defence Policy, Strategy and Planning Division, Financial Management Division, Departmental Planning and Budget Evaluation Committee, the Defence Planning Board and the Operations Board. See DoD SBP 2005-2008 19 Figure 3.2 and DoD SBP 200719 Figure 3.2. See also http://www.ppdiv.mil.za (accessed 2008-09-19). Eg, Norwegian Directive s 4.2, which incorporates representatives of the Section for Operative Planning of the Department of Operational and Emergency Response Planning, the Joint Operative Headquarters, the Defence Staff College, Army Matériel Command, the Defence Logistical Organization and the Defence Research Institute into the review Committee and if required independent experts may be involved. See further Daoust et al June 200284 IRRC 355 and US Department of the Air Force Memorandum for AAC/JAQ (Mr Luthy) from AF/JA "Requested Legal Review of the Massive Ordinance Air Blast (MOAB) Weapon" 21 March 20035.

42 See Belgian Order s 4(c); Norwegian Directive s 4.3; Danish RC Report 28; and http://www.sweden.gov.se/sb/d/2060/a/28161 (accessed 2008-08-15).

43 See "Report of the ICRC for the review conference of the 1980 UN conventions on Prohibitions or restrictions on the use of certain conventional weapons which may be deemed to be excessively injurious or to have indiscriminate effects" April 1994299 IRRC 123-182. 


\section{Initiation of the review}

To ensure South Africa's compliance with Article 36, it must be made compulsory that each of the authorities responsible for acquisition or modification of a weapon submits the matter to the review body for a legal review at each of the phases identified below. ${ }^{44}$ Upon submission of the notification, ${ }^{45}$ the body must initiate the review process in regard to the weapon. ${ }^{46}$ In the absence of such a notification, the body should be empowered to undertake a review on its own initiative. ${ }^{47}$ Such power would ensure that weapons will not "escape" review simply because no notification was given regarding the acquisition or modification of the weapon.

Armscor, and in particular its monthly Contracts Bulletin ${ }^{48}$ and secure daily electronic bulletin, ${ }^{49}$ will be a vitally important source of information regarding weapons acquisition proposals and contracts. In addition, the National Conventional Weapons Committee ${ }^{50}$ and the Directorate Conventional Arms Control $^{51}$ are important sources of information regarding the registration of conventional weapons traders and the authorization and issuing of the necessary permits to such traders. ${ }^{52}$ These sources would allow the review body a means of identifying situations where a notification has not been received.

Where South Africa purchases weapons, either from the private sector, including "off-the-shelf" procurement, or from another state, it is under the obligation to conduct its own review of the weapon considered for acquisition; it cannot rely solely on the seller's assurances and documentation nor on an evaluation conducted by another state. ${ }^{53}$ In this situation, the Republic must review the legality of the weapon proposed for purchase prior to entering into any purchasing agreement and at the stage of the study of the weapon. ${ }^{54}$

At all times during the review process, the review body must be cognisant of the methods of warfare that are proposed or expected to be associated with the weapon. ${ }^{55}$ If at any stage, whether during or after the process of

44 See par 63 below. See Lawand et al 23; and McClelland June 200385 IRRC 25.

45 See Swedish Ordinance s 9; Norwegian Directive s 4.6; Australian Instruction s 7-8; and Belgian Order s 5(b).

46 See ICRC Advisory Service 1.

47 See Norwegian Directive s 4.3; Danish RC Report 28; and Daoust et al June 200284 IRRC 355.

48 An Armaments Corporation of South Africa publication containing all requests for proposals and bids awarded regarding the acquisition of weapons.

49 See http://www.dod.mil.za and http://www.armscor.co.za/abs/userhome.asp.

$50 \mathrm{~S} 2$ of the Established by National Conventional Arms Control Act 41 of 2002.

51 National Conventional Arms Control Act 41 of $2002 \mathrm{~s} 8$.

52 National Conventional Arms Control Act s 13-14. See also GN R634 of 2004-05-28.

53 Sandoz et al 1473; and McClelland June 200385 IRRC 411. See also UK Ministry of Defence The Manual of the Law of Armed Conflict (2004) (hereinafter "UK Military Manual") 1196.20 .1$.

54 Lawand et al 24. See also Belgian Order s 5(a); and Daoust June 200183 IRRC 540. See further ICRC Advisory Service 1.

55 Lawand et al 24. 
acquisition, new evidence arises regarding the operational performance or effects of the weapon, a new review process should be initiated. ${ }^{56}$

\section{Integration into the weapons acquisition process}

States are obligated to assess the legality of weapons during their "study, development, acquisition or adoption". ${ }^{77}$ This obligation encompasses the entire weapons acquisition process. Furthermore, it has been submitted that the wording of Article 36 suggests that an assessment as to the legality of a weapon is to be made at each of the successive stages listed in the Article. ${ }^{58}$

The legal review of a weapon should take place at the earliest possible stage ${ }^{59}$ of this acquisition process, for not only is this required by Article $36,{ }^{60}$ but this will also result in the avoidance of costly advances in the acquisition process, a process which can take several years, where the weapon may be unusable due to unlawfulness. ${ }^{61}$ This also applies in the case of a state adopting a technical modification to an existing weapon. ${ }^{62}$

The weapons acquisition process is complex, but can be discerned into three phases, namely the research phase, development phase and acquisition phase.$^{63}$ If the process of reviewing the legality of weapons is to be carried out correctly, it must be integrated into and understand the acquisition process itself. ${ }^{64}$

\section{- Research phase}

The beginning of the weapons acquisition process is an assessment of what the capability gap is that the military wishes to fill. ${ }^{65}$ It must be discerned what the military wishes to achieve that it cannot achieve with its current weapons arsenal. ${ }^{66}$ Once the capability gap is discerned, a weapons concept will be developed. This concept will then undergo a period of scientific study, where it is further refined and its characteristics delineated. ${ }^{67}$

See Belgian Order s 5(i); and Norwegian Directive s 2.3.

Additional Protocol I Article 36.

Levie Protection of War Victims: Protocol I to the 1949 Geneva Conventions (1980) 285.

59 The earliest stage should ideally be the research phase and, at the least, prior to the adoption, acquisition and deployment of the weapon. See Daoust et al June 200284 IRRC 351, 357 and 361; Daoust June 200183 IRRC 540; Belgian Order s 5(a); Norwegian Directive s 2.3; UK Military Manual 119 6.20.1; US Air Force Instruction s 1.1.1-1.1.2; US Instruction; US Department of Air Force Policy Directive 51-4, Compliance with the Law of Armed Conflict, 26 April 1993 par 1.4; Toth 2006 MJIL 22-40; and MOAB Review 2.b. Daoust et al June 200284 IRRC 355.

61 Lawand et al 24; and McClelland June 200385 IRRC 406 and 413. See also ICRC Advisory Service 1; Daoust June 200183 IRRC 542; and Daoust et al June 200284 IRRC 351 and 361.

62 See US Air Force Instruction s 1.1.1; and Australian Instruction s 10. See also Sandoz et al 1473; and UK Military Manual 119 6.20.1.

63 Lawand et al 23; and McClelland June 200385 IRRC 401. See Daoust et al June 200284 IRRC 357.

64 McClelland June 200385 IRRC 401

65 See Norwegian Directive s 2.3

66 McClelland June 200385 IRRC 401.

67 Lawand et al 23; and McClelland June 200385 IRRC 401. 


\section{- Development phase}

Next, there follows the development phase, which entails the development and testing of prototypes. ${ }^{68}$ Once initial testing of the prototype has proved the concept viable, extensive and rigorous testing of the prototype will follow. ${ }^{69}$

\section{- Acquisition phase}

Once the weapon has successfully passed the development phase, manufacturing and acquisition of the weapon will take place. ${ }^{70}$ It is at this phase that the weapon enters military service. As new batches of the weapon are produced, further testing will be conducted. ${ }^{71}$

Where a state produces its own weapons, or where it adopts a technical modification to an existing weapon, the review process should begin at and be integrated into the research phase at the concept stage. ${ }^{72}$ This will ensure compliance with the requirement that the review of the weapon must take place at the earliest possible stage. ${ }^{73}$ However, it is not sufficient that the review begins and ends at the concept stage. Throughout the acquisition process, the legal position and the design and planned use of the weapon could change during any of its phases. ${ }^{74}$ Thus, it follows that the review process should be fully integrated into the entire acquisition process, ${ }^{75}$ especially at the main stages of the weapons development. This will ensure that input regarding the legality of the weapon can be given and considered at every decision-making point along the process and that the weapon will be legally compliant at every stage of acquisition, especially at the stage of the weapon's actual integration into the state's military stocks. ${ }^{76}$ Furthermore, additional legal advice could be sought from the review body at any point during the acquisition process. ${ }^{77}$ In addition, a wide range of information is gathered during the acquisition process and with the integration of the review into this process, the body will be able to make use of the documentation, data and evidence produced and gathered by the acquisition process. ${ }^{78}$

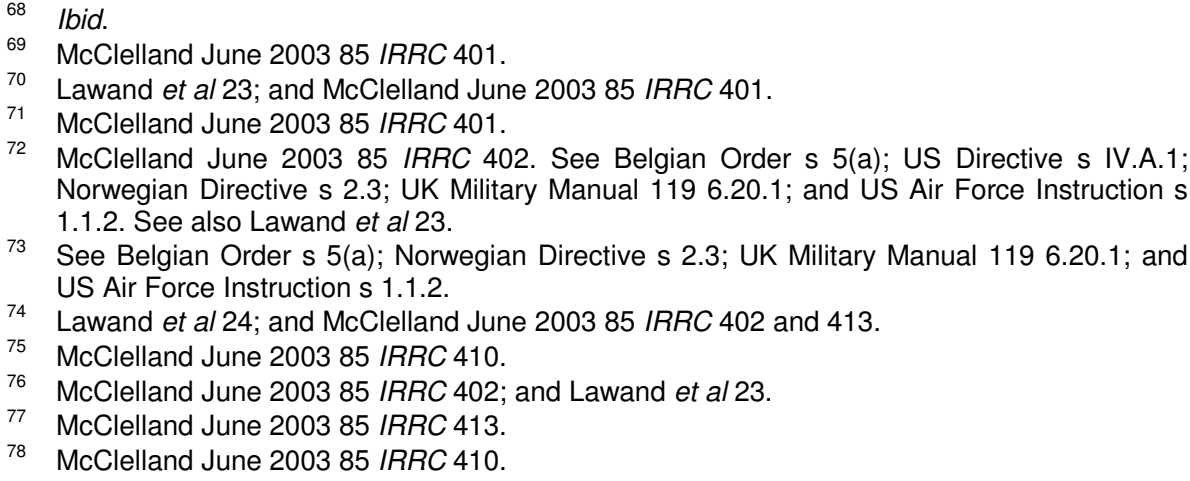
Norwegian Directive s 2.3; UK Military Manual 119 6.20.1; and US Air Force Instruction s 1.1.2. See also Lawand et al 23.

73 See Belgian Order s 5(a); Norwegian Directive s 2.3; UK Military Manual 119 6.20.1; and US Air Force Instruction s 1.1.2.

44 Lawand et al 24; and McClelland June 200385 IRRC 402 and 413.

75 McClelland June 200385 IRRC 410.

76 McClelland June 200385 IRRC 402; and Lawand et al 23.

McClelland June 200385 IRRC 413.

McClelland June 200385 IRRC 410. 


\section{Data collection}

In order to carry out the legal review of a weapon, the authorities responsible for acquiring the new weapon should make available to the review body all relevant data regarding the weapon. ${ }^{79}$ Furthermore, the review body should be empowered to request and obtain any further data that it deems necessary to adequately complete a review. ${ }^{80}$ Also, the body should be able to request further testing and other experiments it deems necessary to carry out the review, ${ }^{81}$ however, such requests should be tempered by considerations of time and budgetary constraints.

The body should also be empowered to request additional data and testing and experimentation from third parties, such as government departments and private institutes not involved in the acquiring of the weapon being reviewed. ${ }^{82}$ Where possible, the experts forming part of the body could present data derived from their own relevant studies.

A problem in the data collection process may be encountered with regard to technical data concerning the weapon. Where the weapon is being developed by the state, or state-owned bodies, ${ }^{83}$ various scientific data dating from the earliest stages of concept and development will exist and be available to the review body. ${ }^{84}$ However, where the weapon is being purchased from another State or private manufacturer, certain scientific data may not be available due to considerations such as the need to protect intellectual property and reasons of national security. ${ }^{85}$ Some scientific data will be available from tests taken to verify the manufacturer's claims; however, such data would be likely to concentrate on the positive aspects of the weapon and would need to be verified independently. ${ }^{86}$

\section{Conclusions}

\section{Procedure}

Within the structure of a standing committee, the ideal situation would be that the body's conclusion regarding the legality of a weapon is reached by consensus. ${ }^{87}$ However, another decision-making procedure should be in place for those cases where consensus cannot be attained, which could

\footnotetext{
Lawand et al 24.

McClelland June 200385 IRRC 401; and Daoust et al June 200284 IRRC 357.

Daoust et al June 200284 IRRC 357.

See Legal Services: Review of Legality of Weapons under International Law, US Department of Army Regulation 27-53, 1 January 1979 (hereinafter "US Army Regulation") s 5(b)(3) and 5(b)(5); Australian Instruction s 6-8; Belgian Order s 5(e); and id 355. Such as the Denel Group of South Africa. See http://www.dod.mil.za.

84 See McClelland June 200385 IRRC 411.

5 McClelland June 200385 IRRC 411-412.

36 McClelland June 200385 IRRC 412.

87 Lawand et al 25. See also Daoust et al June 200284 IRRC 355.
}

83 
include the vesting of a decisive vote in the chair of the committee or a voting procedure.

\section{Binding force}

Owing to the fact that the body will be making a decision regarding the compliance of a weapon with South Africa's international legal obligations, it follows that such acquisition can only continue if the body finds full compliance with such obligations. ${ }^{89}$ If the weapon is found to be noncompliant, the acquisition of said weapon should be stopped as a matter of law. ${ }^{90}$ In the case of in-service weapons, the body should be empowered to order the removal of non-compliant weapons from existing stocks.

In some circumstances, it may be determined that the use of a weapon is prohibited only in certain situations. When this occurs, it is submitted that the body may then attach conditions to its approval of the weapon, such as requiring certain modifications or placing restrictions on the operational use of the weapon. ${ }^{92}$ In such a case, it is imperative that the restrictions placed on the operational use of the weapon are incorporated into the operating procedures for the weapon in question, as this will ensure that combatants making use of the weapon shall be fully informed of its operational restrictions. ${ }^{93}$ Furthermore, the legal advisors attached to the South African National Defence Force should be made aware of all such restrictions so as to enable them to advise their military commanders regarding the operational use of a weapon during times of armed conflict. ${ }^{94}$

Furthermore, the review body should be empowered to delay the acquisition of a weapon where data regarding the weapon are deemed inadequate. ${ }^{95}$

\section{Appeal and review}

It is submitted that the review process should provide for the possibility of appeal and review of its decisions. ${ }^{96}$ Such procedures would ensure that decisions that are incorrect, be it on the merits or in the decision-making

88 Lawand et al 25.

89 Lawand et al 25-26.

90 Ibid; McClelland June 200385 IRRC 403; Parks's Paper 2002; and Daoust et al June 2002 84 IRRC 357. See also Australian Instruction s 5 and 11 and Implementation and Operation of the Defense Acquisition System and the Joint Capabilities Integration and Development System, US Department of Navy, Secretary of the Navy Instruction 5000.2C, 19 November 2004 (hereinafter "US Navy Instruction") s 2.6

91 Daoust et al June 200284 IRRC 357.

92 Lawand et al 26; and Lawand December 200688 IRRC 928. See also Swedish Ordinance s 7.

93 Lawand December 200688 IRRC 928; and Lawand et al 15. See also April 1994 IRRC 123-182.

94 Regarding the provision of legal advisors, see API Article 82; April 1994 IRRC 123-182; Daoust et al June 200284 IRRC 347; and Segall Punishing Violations of International Humanitarian Law at the National Level: A Guide for Common Law States (2001) 21-22.

95 Daoust et al June 200284 IRRC 357.

96 See US Directive subsection IV.C; and Swedish Ordinance s 10. See further ICRC Advisory Service 1. 
process, could be corrected. This would guarantee that the obligation under Article 36 is effected satisfactorily and will further the transparency, accountability and legitimacy of the review process. It must be ensured that the panel responsible for appeals and reviews is qualified in international humanitarian law, in particular the legal rules pertaining to weapons, and that such panel's decisions are based on legal determinations, with cognisance being taken of the relevant multi-disciplinary elements. ${ }^{97}$ It is submitted that the review and appellate panel should be assisted by the relevant experts as required by the subject matter of each appeal or review. However, these assisting experts must not include any of the experts who had formed part of the review body that conducted the weapons review constituting the subject of the appeal or review.

\section{Review records}

\section{Review archive}

It is submitted that archives of the reviews carried out and a formal record of all reviewed weapons should maintained. ${ }^{98}$ Such archives would enable the review body to refer to previous decisions, which would allow for consistency in decision-making. ${ }^{99}$ The keeping of review records would also be a necessity if procedures for appeals and reviews are put into place. Furthermore, where the subject of the review is a modification of a previously reviewed weapon, records of the original weapon's review would greatly aid the review body. ${ }^{100}$ This would similarly apply if existing weapons were being reviewed anew due to changes in law. A formal record of all reviewed weapons would further aid the State in determining which weapons in its arsenal have been reviewed. Thus, the keeping of review records would be an aid to the efficient functioning of the review body. ${ }^{101}$

\section{Access to records}

It is left to the discretion of each state conducting legal reviews as to the level of access to review records that will be afforded and to which persons such access will be granted. ${ }^{102}$ Considerations that will influence the above decision is national legislation regarding access to information; the confidentiality status of the reviewed weapon; the value of transparency amongst different government departments, towards external experts and the public; the obligation for states to ensure respect for international humanitarian law, in particular where it is determined that the use of the

\footnotetext{
97 Lawand et al 26.

98 See US Instruction s IV.A.2; Australian Instruction s 13; [Belgian] Archiefwet, 24 June 1955; and Daoust et al June 200284 IRRC 357. 
weapon under review would contravene international humanitarian law and the value of sharing experience with other states.

Under South African law, everyone has the right of access to any information held by the state. ${ }^{104}$ Furthermore, records relating to aspects of military operations dealing with research, design and development, acquisition, storage, distribution, maintenance, evacuation and disposal of material may be requested from the Department of Defence. ${ }^{105}$

However, access to information may be refused if its disclosure could reasonably be expected to cause prejudice to the defence and security of the Republic, ${ }^{106}$ including information relating to "the quantity, characteristics, capabilities, vulnerabilities or deployment of weapons or any other equipment used for the detection, prevention, suppression or curtailment of subversive or hostile activities; or anything being designed, developed, produced or considered for use as weapons or such other equipment". ${ }^{107}$

In addition, the mandatory protection afforded to commercial information of third parties, including trade secrets and financial, commercial, scientific or technical information, requires that access to such information must be refused when the provisions of PAIA section 36 are met. A similar situation exists with regard to the mandatory protection afforded to third-party research $^{108}$ and the directory protection afforded to research information of a public body. ${ }^{109}$

Thus, with regard to the records of weapons reviews, it is evident that almost all of the empirical data contained in the record would be protected from public access under South African law. ${ }^{110}$ Furthermore, South Africa is under no obligation to make the substantive findings of its reviews public or to share them with other states. ${ }^{11}$

However, it is submitted that the pure legal findings and reasoning of a review would not be subject to the protections mentioned above. Therefore, it is submitted that such information should be made available to the public in order to promote transparency and accountability. ${ }^{112}$ Access to such legal

103 Ibid.

104 Constitution of the Republic of South Africa, 1996 s 32(1)(a); and Promotion of Access to Information Act 2 of 2000 (hereinafter "PAIA") s 9(a)(i). See also PAIA Preamble par 9-10 and s 9 (e)(i) and (iii). Information included under this right are records of a public body. The term public body includes any functionary or institution that exercises a public power or performing a public function in terms of any legislation. See PAIA s 1 and s 3(a).

105 Promotion of Access to Information Manual for the Department of Defence 19.

106 PAIA s 41(1)(a). See also PAIA s 41 in fine. See further McClelland June 200385 IRRC 414.

107 PAIA s 41(2)(b). See also Lawand et al 27; Daoust et al June 200284 IRRC 355; and [Swedish] Sekretesslag, SFS 1980:100.

108 PAIA s 43(1).

109 PAIA S 43(2).

110 See also PAIA Preamble par 7 and s 9(b)(i)-(ii). See further McClelland June 200385 IRRC 414-415.

111 Lawand et al 27.

112 See Constitution, 1996 s 195(1)(f), s 195(1)(g) and s 195(2). See also PAIA Preamble par 9-10, s 9(e)(i) and s 9(e)(iii). See further Daoust et al June 200284 IRRC 361. 
findings and reasoning would then be regulated under the provisions of PAIA. ${ }^{\text {. }}$

Further, the Republic would be required to share information regarding its review procedures with other states party to Additional Protocol I. ${ }^{114}$ The International Committee of the Red Cross has been called upon to facilitate such exchanges. ${ }^{115}$ States have also been encouraged "to promote, wherever possible, exchange of information and transparency in relation to these mechanisms, procedures and evaluations". ${ }^{116}$

\section{In-service legal monitoring}

Once a weapon has been deemed by the review body to be compliant with South Africa's international legal obligations and it enters service, this does not necessarily end the review process. Changes in the law applicable to weapons' legality could occur during the life-span of the weapon. ${ }^{117}$ When such legal changes occur, the weapon would need to be reviewed once more. ${ }^{118}$ The same would occur if the weapon undergoes any modification that alters its function. ${ }^{119}$ Thus, South Africa's in-service weapons would need to be subject to a form of continued legal monitoring. ${ }^{120}$

\section{CONCLUSION}

Owing to the binding effect of Additional Protocol I Article 36 upon South Africa, a weapons legality review process must be established within the national sphere. As no standard is provided for the national implementation of this Article, this article has set out a number of proposals in this regard, which will now be summarised in conclusion.

The material scope of the review encompasses all weapons and weapons systems, and the expected methods by which such weapons would be used and could even be taken to include equipment that does not constitute a weapon as such, but which directly contributes to the offensive capability of

113 See also [Australian] Freedom of Information Act 1982 (9859 of 1982); [Swedish] Tryckfrihetsförordningen, SFS 1949:105; [US] The Freedom of Information Act, 5 U.S.C. and [Belgian] Wet betreffende de openbaarheid van bestuur, 11 April 1994. See further Parks's Paper 2001; Danish RC Report 28; Daoust et al June 200284 IRRC 355 and 357; Daoust June 200183 IRRC 541; and Lawand et al 27.

114 Additional Protocol I Article 84. See Sandoz et al 1470 and fn 12. See further Agenda for Humanitarian Action Action 2.5.3.

115 At the 27th International Conference of the Red Cross and the Red Crescent (Geneva, Switzerland, 31 October-6 November 1999) and the 28th International Conference of the Red Cross and the Red Crescent (Geneva, Switzerland, 2-6 December 2003). See Agenda for Humanitarian Action Action 2.5.3. See further Lawand et al 27-28.

116 Plan of Action for the years 2000-2003 adopted by the 27th International Conference of the Red Cross and Red Crescent (Geneva, Switzerland, 31 October-6 November 1999) s 21, Final Goal 1.5. The Conference also stated that "States and the ICRC may engage consultations to promote these mechanisms". See also Coupland and Herby September 1999835 IRRC 583-592.

117 McClelland June 200385 IRRC 413.

118 See par 23 above.

119 lbid.

120 See McClelland June 200385 IRRC 413. 
an armed force which utilizes it. This scope includes weapons that are not technically and strictly "new".

The review body should take the form of an inter-departmental body established by an Act of Parliament and must take into consideration all the existing international law rules binding upon the Republic regarding weapons and methods of warfare, the Martens Clause and relevant United Nations resolutions. Reasonably foreseeable future developments of the law should also be taken into account.

The body should take the form of a standing committee of permanent and ad hoc experts from a wide variety of fields and drawn from various sources. It must be mandatory that all authorities responsible for weapons acquisition notify the body at each phase of acquisition so that the review process can be initiated. The body must also be empowered to initiate the process on its own initiative.

Where weapons are acquired from the private sector or other states, South Africa must conduct its own review of the weapon concerned prior to entering into any purchasing agreement and at the stage of the study of the weapon proposed for purchase.

The review must take place at the earliest possible stage of the acquisition process. The review must be integrated into the entire acquisition process, with legality assessments being made at each of the successive phases of acquisition.

The authorities responsible for acquiring a weapon must make available to the body all relevant data regarding the weapon. The body must also be empowered to take measures to obtain, from various sources, further necessary data, testing and experimentation, time and budgetary constraints considered. Manufacturers' data should be independently verified.

The body should reach its decisions by consensus. However, an alternate procedure must be in place for those cases where consensus cannot be attained, such as the vesting of a decisive vote in the chair of the committee or a voting procedure. The acquisition of a weapon must be stopped as a matter of law if the body reaches a decision that such weapon is not compliant with South Africa's international legal obligations and the body should be empowered to order the removal of non-compliant weapons from existing weapons stocks. Where the body decides that a weapon is only prohibited in certain situations, it must be empowered to attach necessary conditions to its approval of the weapon. Furthermore, the body should be empowered to delay the acquisition of a weapon where data regarding the weapon are deemed inadequate.

Review decisions should be subject to appeal and review procedures carried out by panels consisting of persons qualified in international humanitarian law, in particular the legal rules pertaining to weapons, and assisted by the necessary experts. Review records must be archived and a formal record of all reviewed weapons should maintained. The majority of the empirical data contained in the record would be protected from public access and no obligation exists to oblige South Africa to make the substantive findings of its reviews public. However, it is submitted that the pure legal findings and reasoning of a review should be made available to 
the public under the provisions of PAIA. Further, the Republic would be required to share information regarding its review procedures with other states party to Additional Protocol l.

Finally, it is submitted that all reviewed weapons must be subjected to continued legal monitoring to ensure their legality throughout their in-service lifespan.

The authors propose these submissions, taken from international and comparative research, as the most efficient and effective means of implementing Additional Protocol I Article 36 within the South African legal and administrative framework. 